DOI: https://doi.org/10.24867/01BE36Stanojevic

\title{
IMPLEMENTACIJA APLIKACIJE ZA ANALIZU POTROŠNJE ELEKTRIČNE ENERGIJE
}

\section{IMPLEMENTATION OF THE APPLICATION FOR POWER CONSUMPTION ANALYTICS}

\author{
Vladimir Stanojević, Fakultet tehničkih nauka, Novi Sad
}

\begin{abstract}
Oblast - ELEKTROTEHNIKA I RAČUNARSTVO
Kratak sadržaj - $U$ radu je prikazana specifikacija $i$ implementacija sistema za analizu potrošnje električne energije i generisanje računa za pametna brojila. Administrator je zadužen za nadgledanje funkcionalnosti $i$ izmena sistema. Uloga pretplatnika je mogućnost detaljnog uvida u potrošnju električne energije.
\end{abstract}

Ključne reči: pametna brojila, merenje potrošnje električne energije, generisanje računa

Abstract - This paper presents the specification and the implementation of a system for analyzing measurement of electricity consumption and generating bills for smart meters. The role of administrator is monitoring all functionalities and changes in system. The role of subscribers is the possibility of a detailed insight into the consumption of electricity.

Keywords: smart meter, energy, measurement of electricity consumption, generating a bill

\section{UVOD}

Aplikacija, čija su specifikacija i implementacija tema ovog rada bavi se analizom potrošnje energije pametnih brojila (engl. smart meter). Pametna brojila su povezana sa koncentratorima i transformatorima, dok su transformatori povezani sa podstanicama. Uloga koncentratora je obuhvat poslatih očitavanja od strane pametnih brojila dok transformatori i podstanice kao zadatak imaju transformaciju napona sa viših vrednosti na niže.

Aplikacija je namenjena za dva tipa korisnika. Prvi tip korisnika predstavlja potrošač koji ima potpisan ugovor sa snabdevačem električne energije, dok drugi tip korisnika predstavlja administrator sistema. Korisnik kao potrošač može imati uvid u potrošnju električne energije za svako brojilo za koje se vodi kao pretplatnik. Administrator sistema ima mogućnost uvida $u$ informacije o pojedinačnim brojilima, transformatorima, koncentratorima i podstanicama. Cilj sistema ovog tipa je da se automatizuje proces formiranja računa za potrošače i da pruži mogućnost analize potrošnje pametnog brojila, transformatora i podstanica.

Analiza potrošnje vrši se sa ciljem uočavanja nepravilnosti u radu brojila, koji mogu biti izazvane od strane čoveka ili samog brojila. Glavni razlog uvođenja

\section{NAPOMENA:}

Ovaj rad proistekao je iz master rada čiji mentor je bio dr Miroslav Zarić. pametnih brojila i praćenja njihovog stanja ogleda se $u$ prednosti uštede energije i održavanja.

\section{OPIS INFORMACIONOG SISTEMA}

Koncept pametnog merenja (smart metering) obuhvata instalaciju pametnih brojila za rezidentne korisnike, nakon čega se vrše očitavanja, procesiranje podataka i evidenciju o potrošnji korisnika [1].

Pametna brojila mogu imati sledeće karakteristike [1]:

- trenutno ili približno trenutno registrovanje potrošnje električne energije

- nude mogućnost očitavanja brojila i lokalno i sa udaljene lokacije

- ograničavanje potrošnje na brojilu sa udaljene lokacije (u ekstremnim situacijama i ukidanje struje korisniku)

- mogućnost očitavanja i drugih tipova brojila (npr. gas, voda)

Pametna brojila su povezana sa koncentratorima i transformatorima.

Koncentratori su posrednici između pametnih brojila i sistema za prikupljanje podataka. Njihova svrha je da smanje količinu mrežnog saobraćaja u sistemu, tj, namenjeni su da sva očitavanja sa pametnih brojila za određeni period uskladište kod sebe, te da ih periodično prosleđuju sistemu za prikupljanje podataka. Često su implementirani tako da koriste radio vezu (RF) za komunikaciju sa sistemom za prikupljanje podataka, dok sa pametnim brojilima komuniciraju putem Wi-Fi mreže. Podstanica je deo sistema za generisanje, prenos i distribuciju električne energije. Podstanice pretvaranju visoki napon u niži. Zadužene su da napone od $33 \mathrm{kV}$ do $11 \mathrm{kV}$ koliko primaju transformatori konvertuju na niže naponske nivoe.

Transformatori transformišu $11 \mathrm{kV}$ na $400-220 \mathrm{~V}$ za upotrebu u domovima.

S obzirom da svu potrošnju energije evidentiraju pametna brojila, kompanije dobijaju realniji i precizniji pregled potrošnje energije u njihovom regionu. Ovaj proces omogućuje ispitivanje sumnjivih područja gde je upotreba energije veća ili manja od očekivanog.

Postoji više zainteresovanih strana za realizaciju instalacije i korišćenja pametnih brojila:

- kompanije koje se bave merenjem potrošnje smanjuju troškove očitavanja brojila

- dobavljači energije smanjuju troškove korisničke podrške i uvode nove mogućnosti korisnicima

- vlade postižu ciljeve uštede energije i efikasnosti

- krajnji korisnici povećavaju energetsku svest i smanjuju potrošnju energije i troškove energije. 
Uvođenje pametnih brojila deluje kao logičan korak u svetu u kojem sve komunikacije teže da se digitalizuju i standardizuju (Internet, E-mail, SMS) i gde troškovi "digitalne inteligencije" postaju konstantno niži.

\section{KORISĆENE TEHNOLOGIJE}

Za razvoj rešenja neke od upotrebljenih tehnologija i alata su ASP.NET okruženje, uz ORM Entity Framework i Spring Boot okruženje, uz Maven. Klijentski (front-end) deo aplikacije bazira se na Java Script-u, jQuery-ju i Bootstrap-u.

Koristi se MS SQL Server uz MS SQL Management Studio za rukovanje bazom podataka. Activiti okruženje se koristi za kreiranje dijagrama. Neke od sledećih tehnologija opisane su u nastavku.

\subsection{ASP.NET}

ASP.NET je javno dostupno okruženje za izgradnju serverske strane web aplikacija. Razvijen je od strane Microsoft korporacije u cilju da se programerima omogući kreiranje dinamičkih web sajtova, web aplikacija, aplikacija i servisa [2].

\subsection{Entity Framework}

Entity Framework 6 (EF6) je objektno relacioni maper (eng. object-relational mapper) za .NET okruženje [3]. Kao ORM, Entity Framework smanjuje neusklađenost između relacionog i objektno orijentisanog pristupa. Omogućuje programerima da kreiraju aplikacije tako da interaguju sa podacima koji su smešteni u relacionu bazu podataka koristeći isključivo .NET objekte.

\subsection{Internet Information Services}

Internet Information Services (IIS, ranije Internet Information Server) je proširivi web server kreiran od strane Microsoft-a za korišćenje sa Windows NT familijom. [4]

\subsection{Spring Boot}

Spring je open-source Java platforma sa izuzetno kvalitetnom podrškom za razvoj aplikacija. Programiranje $\mathrm{u}$ Springu je vezano za koncepte Inversion of control i Dependency Injection. Ovi koncepti obezbeđuju kreiranje loosely-coupled objekata i njihovo automatsko povezivanje u aplikacionu celinu od strane okruženja [5].

\section{5 jQuery}

jQuery je JavaScript biblioteka i može da se koristi na više platformi. Dizajnirana je da klijentsku stranu uprosti uz korišćenje $H T M L$-a [6]. Sintaksa jQuery biblioteke dizajnirana je da uprosti navigaciju kroz dokument odabirom DOM elemenata, da kreira animacije, rukuje događajima i koristi Ajax pozive.

\subsection{Activiti}

Activiti je jednostavna Business Process Management $(B P M)$ platforma korišćena uglavnom od strane programera i sistem administratora. Automatizacija ovih procesa omogućava brži razvoj i kompanija zauzima prednost u odnosu na konkurente. Postoji veliki broj alata koji se koriste za automatizaciju, ali Alfresco Activiti, ili njegova javno dostupna verzija Activiti, pruža dobre mogućnosti. Osnovni cilj BPMN jeste da omogući standardnu notaciju razumljivu svim učesnicima $u$ procesu. Tu su uključeni poslovni analitičari koji kreiraju i menjaju procese, programeri zaduženi za implementaciju i menadžeri procesa koji procese nadgledaju i upravljaju njima. $B P M N$ se predstavlja kao zajednički jezik koji savladava komunikacioni jaz koji se često javlja između dizajna poslovnog procesa i njegove implementacije.

\section{IMPLEMENTACIJA I DEMONSTRACIJA}

Kao početni korak u procesu implementacije softverskog rešenja neophodno je projektovati sistem i modelovati bazu podataka sa kojom će se rukovati. Razvoj konceptualnog modela omogućava razumevanje entitetea na kojima se zasniva rad sistema Iz ovog modela tj. iz njegovih relacija entiteti-veze dobija se relaciona baza podataka.

Na slici 1. prikazan je konceptualni dijagram sistema.

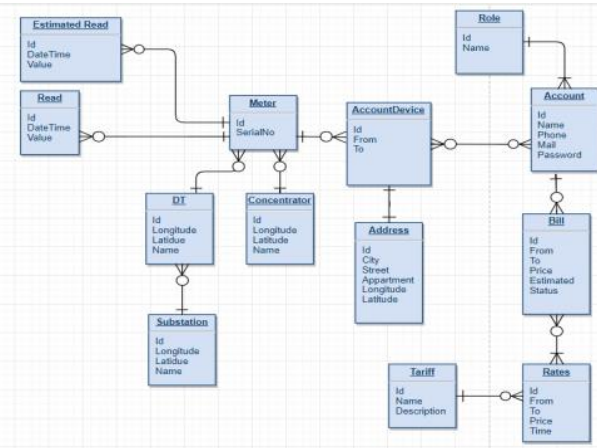

Slika 1. Konceptualni dijagram

U ovoj sekciji takođe su prikazan i procesi implementirani u sistemu i to su:

- Grafički prikaz pozicija podstanica, transformatora, koncentratora i pametnih brojila iz sistema pomoću Google mapa

- Prikaz osnovnih informacija za odabranu podstanicu sa mape

- Prikaz povezanih pametnih brojila za odabrani koncentrator

- Prikaz osnovnih informacija za odabrano brojilo sa mape

- Tabelarni prikaz potrošnje svih brojila na osnovu izabranog transformatora i perioda očitavanja

- Prikaz svih brojila za koje je pretplatnik vezan

- Prikaz potrošnje odabranog brojila za pretplatnika

- Pretraga elemenata na mapi

\subsection{Grafički prikaz pozicija podstanica, transformatora, koncentratora i pametnih brojila iz sistema pomoću Google mapa}

Funkcionalnost grafičkog prikaza podrazumeva učitavanje Google mape na kojoj su prikazane lokacije podstanica, transformatora, koncentratora i pametnih brojila. 
Odabirom jedne od ponuđenih podstanica, na mapi se prikazuju svi transformatori sa kojim je odabrana podstanica povezana. Primer grafičkog prikaza podstanice sa povezanim transformatorima nalazi se na slici 2 .

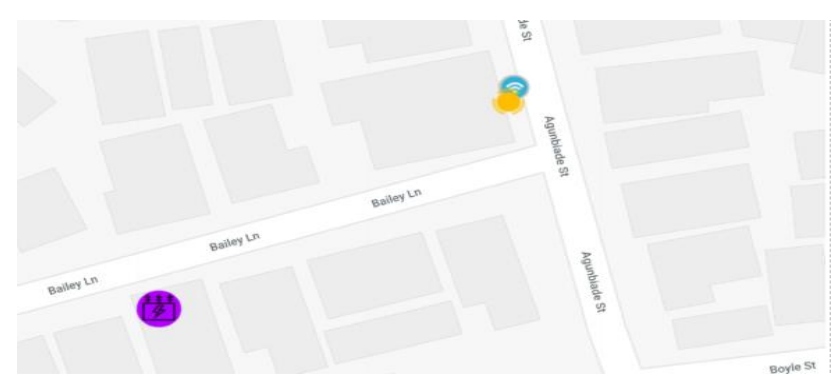

Slika 2. Grafički prikaz podstanice i povezanih transformatora

\subsection{Prikaz osnovnih informacija za odabranu podstanicu sa mape}

Odabirom podstanice objekta na mapi dobija se informacija o imenu, geografskoj širini i dužini i vremenu zadnjeg pristiglog očitavanja podstanice. Osim prikaza, omogućena je i pretraga potrošnje po datumu. Pretraga po datumu prikazuje potrošnju podstanice za odabrani vremenski period, ali i potrošnju povezanih transformatora. Informacije o podstanici i prikaz podstanice dat je na slici 3 .

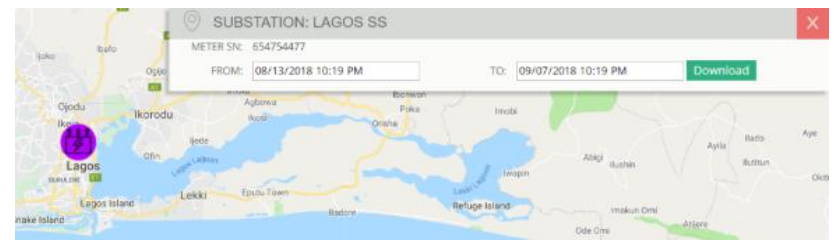

Slika 3. Osnovne informacije o podstanici i pretraga potrošnje

\subsection{Prikaz osnovnih informacija za odabrani transformator sa mape}

Informacije koje se prikazuju administratoru su ime, geografska širina i dužina i vreme zadnjeg pristiglog očitavanja transformatora.

Osim informacija, administratoru se prikazuju i pametna brojila povezana sa odabranim transformatorom na mapi.

Omogućena je i pretraga po datumu, koja za rezultat daje potrošnju transformatora i brojila vezanih za odabranu stanicu. Forma za pretragu prikazana je na slici 4 .

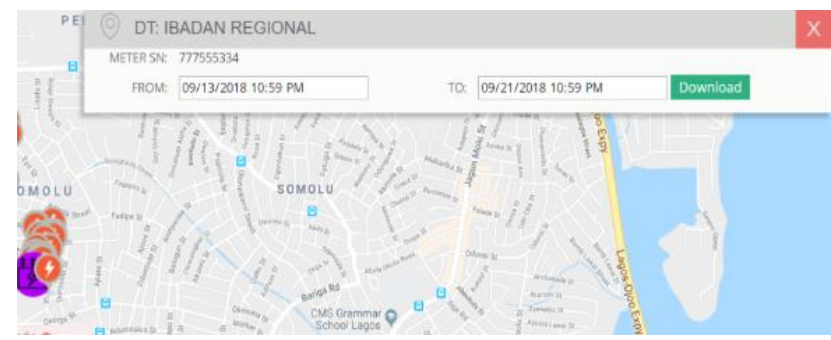

Slika 4. Osnovne informacije o odabranom transformatoru i pretraga potrošnje

\subsection{Prikaz osnovnih informacija za odabrano brojilo} sa mape

Kada se na mapi formiraju objekti koji reprezentuju pametna brojila, administrator poseduje mogućnost da odabere prikaz informacija o pametnom brojilu. Na taj način dobija informacije o imenu, geografskoj širini i dužini i vremenu zadnjeg pristiglog očitavanja pametnog brojila. Informacije vezane za određeni datum dobijaju se pretragom po datumu. Prikaz i rezultat pretrage nalazi se na slici 5 .

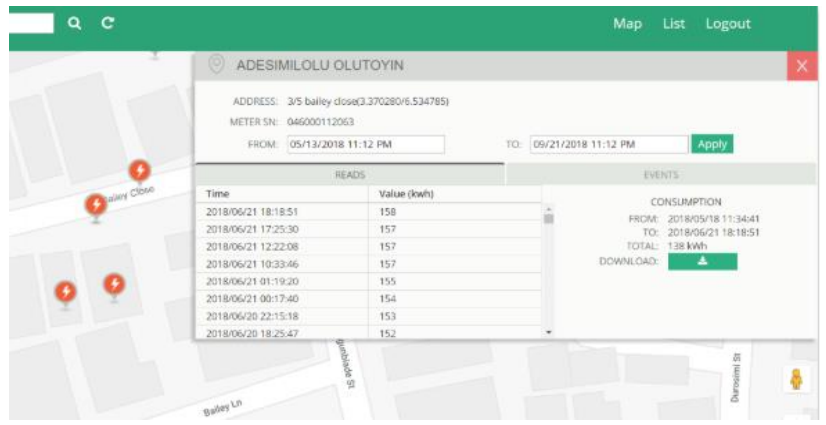

Slika 5. Prikaz osnovnih informacija o pametnom brojilu pretraga i očitavanja brojila

\subsection{Tabelarni prikaz potrošnje svih brojila na osnovu izabranog transformatora i perioda očitavanja}

Na osnovu odabranog transformatora i perioda očitavanja vrši se prikaz brojila. U tabelarnom prikazu, koji se nalazi odvojeno od mape, prikazan je rezultat ove pretrage. Tabela se sastoji od serijskog broja brojila, imena pretplatnika, vremena poslednjeg pristiglog očitavanja, ukupne potrošnje brojila od postavljanja, ukupne potrošnja brojila $u$ navedenom periodu i naziva transformatora kojem pripada. Omogućena je opcija prikaza brojila za sve transformatore i primer je dat na slici 6 .

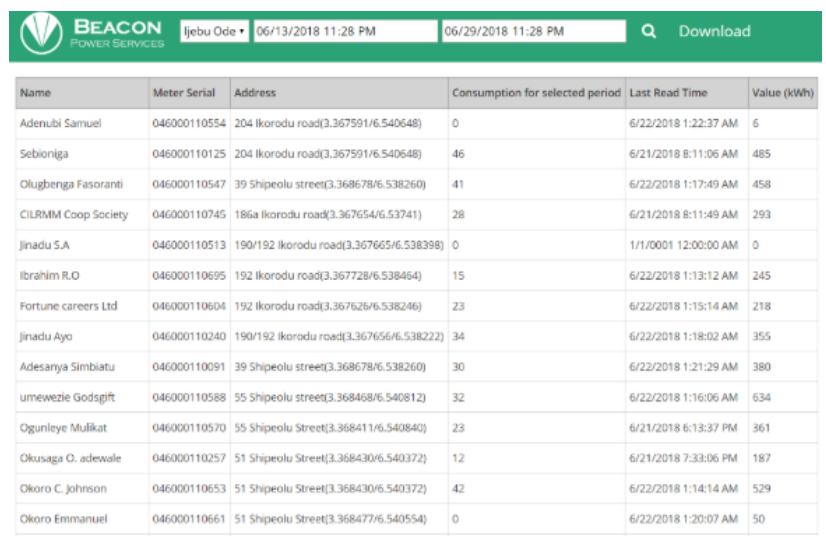

Slika 6. Tabelarni prikaz potrošnje svih brojila odabranog transformatora

\subsection{Prikaz svih brojila za koje je pretplatnik vezan}

Nakon prijave na sistem, pretplatniku se formira tabela sa brojilima na koje je pretplaćen. Na ovom mestu ima uvid $\mathrm{u}$ datum početka pretplate, serijski broj brojila i adresu na koju je brojilo postavljeno. Prikaz informacija o brojilima pretplatnika dat je na slici 7 . 


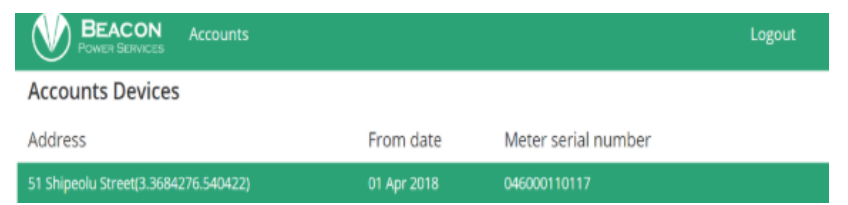

Slika 7. Prikaz brojila koji pripadaju pretplatniku

\subsection{Prikaz potrošnje odabranog brojila za pretplatnika}

Pretplatnik ima mogućnost da, nakon pregleda tabele sa brojilima na koje je pretplaćen, odabere prikaz očitavanja za odabrano brojilo. Potrošnja koja je prikazana predstavlja ukupnu potrošnju od ugradnje brojila do trenutku kada je merenje izvršeno i prikazana je na slici 8 .

\begin{tabular}{|c|c|}
\hline (1) BEACON Accounts & 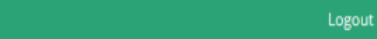 \\
\hline Time & Value \\
\hline 05/24/201800:00 & $59 \mathrm{~W} / \mathrm{h}$ \\
\hline 05/23/2018 23:02 & $59 \mathrm{~W} / \mathrm{h}$ \\
\hline $05 / 22 / 201823: 43$ & $59 \mathrm{~W} / \mathrm{h}$ \\
\hline 05/2222018 20:06 & $58 \mathrm{~W} / \mathrm{h}$ \\
\hline 05/22/2018 16:04 & $58 \mathrm{~W} / \mathrm{h}$ \\
\hline 05/22/2018 09:51 & $58 \mathrm{~W} / \mathrm{h}$ \\
\hline 05/22/2018 08:41 & $58 \mathrm{~W} / \mathrm{h}$ \\
\hline 05/22/201805:36 & $57 \mathrm{~W} / \mathrm{h}$ \\
\hline 05/21/201822:37 & $57 \mathrm{~W} / \mathrm{h}$ \\
\hline $05 / 21 / 201815: 26$ & $57 \mathrm{~W} / \mathrm{h}$ \\
\hline $05 / 21 / 201808: 26$ & $57 \mathrm{~W} / \mathrm{h}$ \\
\hline 05/20/2018 15:54 & $56 \mathrm{~W} / \mathrm{h}$ \\
\hline
\end{tabular}

Slika 8. Tabelarni prikaz potrošnje odabranog brojila

\subsection{Pretraga elemenata na mapi}

Administrator sistema ima mogućnost da pretražuje elemente koji se nalaze na mapi po bilo kom njihobom atributu.

\section{ZAKLJUČAK}

Glavni razlog za uvođenje smart meteringa ogleda se u mogućnosti uštede energije i sigurnosti snabdevanja. Mnogo država iz EU i izvan nje već su uključene u projekte sa pametnim brojilima na demonstracionom nivou ili više od toga.
Pokazano je da je smart metering tehnički izvodljiv i da nema prepreka za uvođenje pametnih brojila. Korisnici pametnih brojila u svakom trenutku mogu videti svoju trenutnu potrošnju te mogu prilagoditi potrošnju u cilju smanjenja troškova.

\section{LITERATURA}

[1] Rob van Gerwen, Saskia Jaarsma and Rob Wilhite, KEMA (2016),,Smart metering”[Internet] Dostupno na :https://idc-

online.com/technical_references/pdfs/electrical_engin eering/Smart_Metering.pdf

[2] Microsoft. May 14, 2013. "ASP.NET is part of a great open source .NET community".

[3] Krill, Paul (20 July 2012). "Microsoft open-sources Entity Framework".

[4] TechNet. Microsoft. "Running IIS 6.0 as an Application Server (IIS 6.0)"

[5] Almir Pehratović (2017). „Uvod u SpringFramework“ [Internet] Dostupno na: https://www.info.ba/ostalo/specijal/8291/uvod-uspring-framework

[6] The jQuery Project. "jQuery: The write less, do more, JavaScript library"

\section{Kratka biografija:}

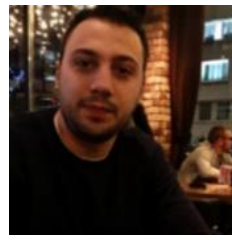

Vladimir Stanojević rođen je 17.09.1994. godine u Ljuboviji. Master rad na Fakultetu tehničkih nauka iz oblasti Elektrotehnike i računarstva - Računarstvo i automatika odbranio je 2018. god.

Kontakt: vladimir94@gmail.com 